\title{
The morphologic left ventricle that requires training by means of pulmonary artery banding before the double-switch procedure for congenitally corrected transposition of the great arteries is at risk of late dysfunction
}

David W. Quinn, FRCS, ${ }^{\text {a }}$ Simon P. McGuirk, FRCS $^{\text {a }}$ Chetan Metha, MRCP, ${ }^{\mathrm{b}}$ Peter Nightingale, $\mathrm{PhD}^{\mathrm{c}}{ }^{\mathrm{c}}$ Joseph V. de Giovanni, FRCP, ${ }^{\text {b }}$ Rami Dhillon, MRCP, ${ }^{\text {b }}$ Paul Miller, MRCS, ${ }^{\text {, }}$ Oliver Stumper, MD, ${ }^{\text {b }}$ John G. Wright, FRCP, ${ }^{b}$ David J. Barron, MD, FRCS, ${ }^{\text {a }}$ and William J. Brawn, FRCS, FRACS ${ }^{a}$

Supplemental material is available online.
From the Departments of Cardiac Surgery ${ }^{a}$ and Paediatric Cardiology, ${ }^{\mathrm{b}}$ Birmingham Children's Hospital NHS Trust, Birmingham, United Kingdom, and the Department of Medical Statistics, ${ }^{\mathrm{c}}$ Wolfson Computer Centre, University Hospital, Birmingham NHS Trust, Birmingham, United Kingdom.

Read at the Eighty-seventh Annual Meeting of The American Association for Thoracic Surgery, Washington, DC, May 5-7, 2007.

Received for publication July 24, 2007; revisions received Jan 25, 2008; accepted for publication Feb 11, 2008.

Address for reprints: William J. Brawn, FRCS, FRACS, Department of Cardiac Surgery, Birmingham Children's Hospital NHS Trust, Steelhouse Lane, Birmingham B4 6NH, United Kingdom (E-mail: william. brawn@bch.nhs.uk).

J Thorac Cardiovasc Surg 2008;135:113744

$0022-5223 / \$ 34.00$

Copyright $\odot 2008$ by The American Association for Thoracic Surgery

doi:10.1016/j.jtcvs.2008.02.017
Objective: The aim of this study was to compare the outcome of the double-switch procedure for congenitally corrected transposition of the great arteries for patients completing morphologic left ventricle training by means of pulmonary artery banding with the outcome of patients whose morphologic left ventricle did not require training.

Methods: A retrospective study of all patients undergoing the double-switch procedure from 1991 through 2004 was performed. Patients were divided into 2 groups: those not requiring morphologic left ventricle training $(n=33)$ and those completing morphologic left ventricle training by means of pulmonary artery banding $(n=11)$.

Results: The time spent with the morphologic left ventricle conditioned at systemic pressures was longer for the group not requiring morphologic left ventricle training (median, 730 days; interquartile range, 399-1234 vs median, 436 days; interquartile range, 411-646; $P=.19$ ). The overall mortality (not requiring morphologic left ventricle training, $12.1 \%$; requiring morphologic left ventricle training, $9.1 \% ; P=1$ ) and rate of death/transplantation, development of moderate-to-severe morphologic left ventricle dysfunction, or both (not requiring morphologic left ventricle training, $21.2 \%$; requiring morphologic left ventricle training, $45.5 \% ; P=.14$ ) were similar between groups. Actuarial freedom from death/transplantation with good morphologic left ventricular function was superior for patients whose morphologic left ventricle did not require training $(P=.04)$. The follow-up was not different between groups (not requiring training: median, 1435 days [interquartile range, 285-2570 days]; requiring morphologic left ventricle training: median, 568 days [interquartile range, 399-1465 days]; $P=.14$ ). On multivariate analysis, the completion of morphologic left ventricle training predicted death/transplantation, development of moderate-to-severe morphologic left ventricle dysfunction, or both $(P=.02)$.

Conclusions: The early results of the double-switch procedure in patients whose morphologic left ventricle required training compare favorably with those of patients whose morphologic left ventricle required no training. There is an increased risk of deterioration of morphologic left ventricle function over time in patients whose morphologic left ventricle requires training, and these patients need to be followed up regularly to detect this.

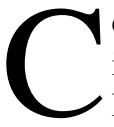
ongenitally corrected transposition of the great arteries (CCTGA) is characterized by atrioventricular and ventriculoarterial discordance. The morphologic left ventricle $(\mathrm{mLV})$ and morphologic right ventricle $(\mathrm{mRV})$ support the pulmonary and systemic circulations, respectively. CCTGA can be associated with 


$$
\begin{aligned}
& \text { Abbreviations and Acronyms } \\
& \mathrm{AR}=\text { aortic regurgitation } \\
& \mathrm{CCF}=\text { congestive cardiac failure } \\
& \text { CCTGA = congenitally corrected transposition } \\
& \text { of the great arteries } \\
& \mathrm{CPB}=\text { cardiopulmonary bypass } \\
& \text { DS } \quad=\text { double-switch } \\
& \text { IQR = interquartile range } \\
& \text { ITU = intensive therapy unit } \\
& \mathrm{mLV}=\text { morphologic left ventricle } \\
& \text { mLVOTO }=\text { morphologic left ventricular outflow } \\
& \text { tract obstruction } \\
& \mathrm{mRV} \quad=\text { morphologic right ventricle } \\
& \text { neoAR = new aortic valve } \\
& \text { PA }=\text { pulmonary artery } \\
& \text { PHT = pulmonary hypertension } \\
& \text { TR = tricuspid regurgitation } \\
& \text { VSD }=\text { ventricular septal defect } \\
& \text { 95\% CL }=95 \% \text { confidence limits }
\end{aligned}
$$

ventricular septal defects (VSDs), morphologic left ventricular outflow tract obstruction (mLVOTO), and tricuspid valve dysplasia. $^{1,2}$

Conventional management can require repair of these associated intracardiac lesions. This leaves the $\mathrm{mRV}$ in the systemic circulation, a task for which its anatomy and coronary blood supply might be unsuited, ${ }^{3,4}$ and is associated with progressive mRV dysfunction and tricuspid regurgitation (TR $)^{5-8}$ and a reported survival at 1 year of $84 \%$, decreasing to $60 \%$ at 15 years. $^{9}$

This poor outcome has increased interest in operations that restore the $\mathrm{mRV}$ and $\mathrm{mLV}$ to their respective pulmonary and systemic circulations. This is achieved by combining an atrial with an arterial switch, the double-switch (DS) procedure. ${ }^{10}$ Although no randomized prospective trial has compared conventional repair with the DS procedure, clinical series suggest that the DS procedure is associated with a low operative mortality, superior survival, and New York Heart Association functional class. ${ }^{10-12}$

A successful DS procedure depends on the mLV's ability to support the systemic circulation. If the mLV has been exposed to systemic pressures from birth, either by virtue of an unrestrictive VSD, congestive cardiac failure (CCF) with associated pulmonary hypertension (PHT), or both, it remains conditioned and capable of sustaining systemic pressures after the DS procedure. In the absence of these abnormalities or after conventional repair, the mLV performs within the lower-resistance pulmonary circulation, and its contractile mass involutes. In these circumstances the $\mathrm{mLV}$ will fail after restoration to the systemic circulation.

The $\mathrm{mLV}$ can be trained to support the systemic circulation by applying a pulmonary artery (PA) band to increase its afterload, expose it to (near-) systemic pressures, and stimulate
mLV hypertrophy. ${ }^{13}$ Concerns exist that patients undergoing the DS procedure after $\mathrm{mLV}$ training by means of PA banding might have earlier $\mathrm{mLV}$ dysfunction than those not requiring training. ${ }^{11,13,14}$ The aim of this study was to compare the results between patients whose $\mathrm{mLV}$ required training by means of PA banding and those whose mLV required no training.

\section{Materials and Methods}

A retrospective review of the notes was conducted on all patients undergoing the DS procedure at a single center from November 1991 through August 2004. Patients were divided into 2 groups according to the requirement for $\mathrm{mLV}$ training (Figure E1). Patients whose $\mathrm{mLV}$ required no training $(\mathrm{n}=33)$ were those who had maintained systemic mLV pressures from birth. These patients had an unrestrictive VSD but required protective PA banding to reduce excessive pulmonary blood flow $(\mathrm{n}=19)$, had unrestrictive VSD but with mLVOTO that provided inherent protection from excessive pulmonary blood flow $(n=3)$, or had established CCF/PHT $(n=11)$. The latter group included 2 patients who had CCF/PHT after conventional repair before referral to our institution. Patients in the trained mLV group $(\mathrm{n}=11)$ had a restrictive VSD or intact septum and had successfully completed mLV training by means of PA banding.

\section{Data Collection}

Demographic, diagnostic, operative, investigative, and follow-up details were recorded. The $\mathrm{mLV}$ conditioning time was the time the ventricle was subjected to systemic pressures before the DS procedure. For the group not requiring training, this was from the date of birth to the DS procedure, and for the group requiring training, this was from the date of first banding to the DS procedure.

The method of assessing ventricular and valvular function was echocardiography. Results were obtained from the reports submitted by the referring center or from echocardiograms obtained by our own department. An independent blinded cardiologist (CM) reviewed all available echocardiograms to avoid interobserver error and bias from knowledge of the clinical situation. Severity of valvular regurgitation was graded as none, mild, moderate, or severe. Ventricular function was scored as good function or moderate or severe dysfunction. The posterior wall thickness (in millimeters) of the mLV was measured by using the electronic caliper technique.

Inotrope use and left atrial measurements after the DS procedure were recorded at arrival in the intensive therapy unit (ITU) and 48 hours later. Inotrope scores were calculated as follows: Dobutamine dose $(\mu \mathrm{g} / \mathrm{kg} / \mathrm{min})+(30 \times$ Milrinonedose $[\mu \mathrm{g} / \mathrm{kg} /$ $\min ])+(100 \times$ Adrenaline dose $[\mu \mathrm{g} / \mathrm{kg} / \mathrm{min}]) .{ }^{15}$ Early mortality was defined as death 30 days or sooner after surgical intervention or before hospital discharge. The New York Heart Association functional scale was used to determine the symptomatic status of patients. Duration of follow-up was defined as days from the DS procedure until the last documented clinical assessment.

\section{Data Analysis}

Data were analyzed by using SPSS software (version 12; SPSS, Inc, Chicago, Ill). Categorical or ordinal data are expressed as a percentage that accounts for missing data, and comparisons were made by using the $\chi^{2}$, Fisher exact, or Kendall $\tau$ b tests, respectively. 
Continuous data are presented as means (95\% confidence limits [95\% CL]) or medians (25\%-75\% interquartile ranges [IQRs]). Normally distributed data were compared by using independent $t$ tests. Skewed data were logarithmically transformed or analyzed nonparametrically. Actuarial freedom from event after the DS procedure was estimated by using the Kaplan-Meier method, and groups were compared by using the Breslow test. Events were defined as death/ transplantation, the development of moderate-to-severe $\mathrm{mLV}$ dysfunction, or both. The time to development of mLV dysfunction depended on the frequency of assessment. To account for this, the time to event was analyzed by using 3 alternatives: the time from the DS procedure to the last report identifying good $\mathrm{mLV}$ function (date of the DS procedure if moderate-to-severe $\mathrm{mLV}$ dysfunction persisted); the time from the DS procedure to the first report identifying moderate-to-severe $\mathrm{mLV}$ dysfunction; and finally, the mean delay between these 2 . All event curves were similarly significant $(P=.03, .04$, and .04$)$, and the first report identifying moderateto-severe $\mathrm{mLV}$ dysfunction was used. The multivariate analysis was performed by using Cox regression.

\section{PA Banding Technique for $\mathbf{m L V}$ Training}

The technique for PA banding for mLV training has been described previously. ${ }^{12,16}$ The band was applied to increase the $\mathrm{mLV}$ pressure to $66 \%$ to $80 \%$ of systemic value while maintaining adequate $\mathrm{mLV}$ systolic function. The $\mathrm{mLV}$ pressure was monitored during and for 12 to 24 hours after the operation by using an indwelling $\mathrm{mLV}$ line and was supported by intravenous dobutamine infusion $\left(\leq 10 \mu \mathrm{g} \cdot \mathrm{kg}^{-1} \cdot \mathrm{min}^{-1}\right)$. Early rebanding was considered if the $\mathrm{mLV} / \mathrm{mRV}$ ratio was less than 0.6. Subsequent assessment for suitability for the DS procedure was by means of transthoracic echocardiography and cardiac catheterization. Progression to the DS procedure was considered when the patient had recovered from surgical intervention and, where possible, had been discharged home and then reviewed by the cardiologist, with cardiac catheterization demonstrating that mLV pressure was at (near-) systemic pressure with moderate-to-good systolic mLV function.

\section{DS Technique}

The technique for the DS procedure has been described previously. ${ }^{12,17}$ Cardiopulmonary bypass (CPB) was instituted by means of caval cannulation with ascending aortic return, myocardial protection was afforded by intermittent cold crystalloid cardioplegia during aortic crossclamping, and the operation was performed with periods of deep hypothermic circulatory arrest. After CPB, echocardiographic assessment was used to gauge the adequacy of the repair. The sternum was closed primarily or temporarily left open with a fenestrated protective polytetrafluoroethylene patch* sutured to the skin to accommodate the size of the heart in anticipation of myocardial dysfunction.

\section{Results}

\section{Total Patient Population}

Forty-four patients underwent the DS procedure during the study period. Their median age was 887.5 days (IQR,

* Gore-Tex patch, registered trademark of W. L. Gore \& Associates, Inc, Newark, Del.
559-2030 days), mean weight was $14.7 \mathrm{~kg}$ (IQR, 12-17.3 kg), and male/female ratio was 3.9:1. The early mortality was 2 (4.5\%) of 44 , the overall mortality was $5(11.4 \%)$ of 44 , and the death/transplantation rate was 7(15.9\%) of 44. Median follow-up was 1269 days (IQR, 175.2-2510.8 days). The actuarial freedom from death/transplantation, moderateto-severe $\mathrm{mLV}$ dysfunction, or both was $84.6 \%$ at 1 year, $80.4 \%$ at 5 years, and $72.3 \%$ at 10 years.

\section{Demographic, Referral, and Anatomic Characteristics}

More information on demographic, referral, and anatomic characteristics is available in Table 1. Age and weight at the time of the DS procedure were greater for the group requiring $\mathrm{mLV}$ training. The incidence of anatomic characteristics was similar. There were no significant differences in the timing of diagnosis. The pattern of referral demonstrated that more patients in the group requiring $\mathrm{mLV}$ training had been referred internationally and fewer had been referred nationally compared with those not requiring training.

\section{Pre-DS Procedure Variables}

More information on pre-DS procedure variables is available in Table 1 . The $\mathrm{mLV} / \mathrm{mRV}$ pressure ratios at cardiac catheterization before the DS procedure were similar in both groups. The conditioning time was longer for those patients not requiring $\mathrm{mLV}$ training, although it did not reach statistical significance. In the group requiring training, posterior wall thickness data were available in 9 patients before PA banding and in 10 patients before the DS procedure. PA banding for $\mathrm{mLV}$ training significantly increased the posterior wall thickness (pre-PA banding mean, $6.2 \mathrm{~mm}$ [95\% CL, 4.8-7.6 mm]; pre-DS procedure mean, $8 \mathrm{~mm}$ [95\% CL, 6.6-9.3 $\mathrm{mm}$ ]; $P=$ .05). Six patients received PA banding for $\mathrm{mLV}$ training but did not undergo the DS procedure in this hospital. One male patient from the international catchment area was lost to follow-up, 2 female patients and 1 male patient PA banded as young adults (ages 15, 20, and 28 years) failed the training program but are alive and well, 1 male patient PA banded at age 12 months and progressing well died from diarrhearelated electrolyte disturbance, and 1 female patient died after a premature DS procedure conducted at another hospital after PA banding at age 5 years.

\section{Operative Characteristics at the Time of the DS Procedure}

More information on operative characteristics at the time of the DS procedure is available in Table 1. There was no difference in the CPB, aortic crossclamping, and deep hypothermic circulatory arrest times in the use of the Jatene repair, the Lecompte maneuver, primary or delayed sternal closure, the incidence of reopening, and the delay to final sternal closure in days between groups. 
TABLE 1. A comparison of the preoperative, operative, and postoperative results of the double-switch procedure between patients completing and those not requiring $\mathrm{mLV}$ training

\begin{tabular}{|c|c|c|c|}
\hline & mLV without training $(\mathrm{n}=33)$ & Trained $\mathrm{mLV}(\mathrm{n}=11) \|$ & $P$ value \\
\hline \multicolumn{4}{|l|}{ Preoperative variables } \\
\hline Age (d), \| median (IOR) & 730 (399-1234) & $1882(1401.5-2346.5)$ & $<.01$ \\
\hline Weight $(\mathrm{kg}), \|$ mean $(95 \% \mathrm{CL})^{*}$ & $12.9(9.9-16)$ & $19.9(15.2-24.5)$ & $<.01$ \\
\hline Male/female ratio $\|$ & $3 / 1$ & $10 / 1$ & .41 \\
\hline Antenatal diagnosis & $1(3)$ & $2(18.2)$ & .15 \\
\hline Referral catchment & & & .05 \\
\hline Local area & $6(18.2)$ & $3(27.3)$ & \\
\hline National & $17(51.5)$ & $1(9.1)$ & \\
\hline International & $10(30.3)$ & $7(63.6)$ & \\
\hline Situs, n (\%) & & & .25 \\
\hline Solitus & $33(100)$ & $10(90.9)$ & \\
\hline Inversus & $0(0)$ & $1(9.1)$ & \\
\hline Cardiac apex, n (\%) & & & 1 \\
\hline Dextrocardia & $2(6.1)$ & $1(9.1)$ & \\
\hline Mesocardia & 1 (3) & $0(0)$ & \\
\hline Levocardia & $30(90.9)$ & $10(90.9)$ & \\
\hline Atrial septum, n (\%) & & & .85 \\
\hline Intact & $25(75.8)$ & $9(81.8)$ & \\
\hline ASD & $3(9.1)$ & $0(0)$ & \\
\hline PFO & $5(15.1)$ & $2(18.2)$ & \\
\hline Mitral valve, $\mathrm{n}(\%)$ & & & 1 \\
\hline Normal & 32 (97) & $11(100)$ & \\
\hline Dysplasia & $1(3)$ & $0(0)$ & \\
\hline Tricuspid valve, $n(\%)$ & & & 1 \\
\hline Normal & $19(57.6)$ & $7(63.6)$ & \\
\hline Dysplasia/Ebstein's anomaly & $14(42.4)$ & $4(36.4)$ & \\
\hline Ventricular septum, n (\%) & & & $<.01$ \\
\hline Intact & $7(21.2)$ & $8(72.7)$ & \\
\hline Perimembranous & $17(51.5)$ & $3(27.3)$ & \\
\hline Muscular (might be multiple) & $9(27.3)$ & $0(0)$ & \\
\hline Aortic valve cusps, $\mathrm{n}(\%)$ & & & .60 \\
\hline Bicuspid & $3(9.1)$ & $0(0)$ & \\
\hline Tricuspid & $30(90.9)$ & $11(100)$ & \\
\hline Pulmonary valve, $\mathrm{n}(\%)$ & & & 1 \\
\hline Bicuspid & $3(9.1)$ & $1(9.1)$ & \\
\hline Tricuspid & $28(84.8)$ & $10(90.9)$ & \\
\hline Quadricuspid & $2(6.1)$ & $0(0)$ & \\
\hline Coarctation & $8(24.2)$ & $1(9.1)$ & .41 \\
\hline CHB (by time of DS procedure) $\|$ & $6(18.2)$ & $2(18.2)$ & 1 \\
\hline $\mathrm{mLV} / \mathrm{mRV}$ pressure ratio before $\mathrm{DS}$ procedure & $0.97(0.92-1.01)$ & $0.98(0.82-1.1)$ & .85 \\
\hline mLV function before DS procedure, $\| \mathrm{n}(\%)$ & & & 1 \\
\hline Good function & $26(83.9)$ & $10(90.9)$ & \\
\hline Moderate-to-severe function & $5(16.1)$ & $1(9.1)$ & \\
\hline mRV function before DS procedure, $\| \mathrm{n}(\%)$ & & & .5 \\
\hline Good function & $29(96.7)$ & $10(90.9)$ & \\
\hline Moderate-to-severe dysfunction & $1(3.3)$ & $1(9.1)$ & \\
\hline $\mathrm{mLV}$ conditioning time $(\mathrm{d}), \|$ median & $730(399-1234)$ & $436(411-646)$ & .19 \\
\hline \multicolumn{4}{|l|}{ Operative variables } \\
\hline Inotropes/ventilation before DS procedure, $\mathrm{n}(\%)$ & $4(12.1)$ & $0(0)$ & .56 \\
\hline CPB time $(\min ),{ }^{*}$ mean & $185(151-218)$ & 175 (147-202) & .67 \\
\hline AXC time $(\min ),{ }^{*}$ mean & $137(127-147)$ & $128(116-139)$ & .29 \\
\hline DHCA time $(\mathrm{min}){ }^{*}$ mean & $33(25-41)$ & $22(9-36)$ & .38 \\
\hline Delayed sternal closure, n (\%) & $19(57.6)$ & $6(54.5)$ & 1 \\
\hline
\end{tabular}




\begin{tabular}{|c|c|c|c|}
\hline & $\mathrm{mLV}$ without training $(\mathrm{n}=33)$ & Trained $\mathrm{mLV}(\mathrm{n}=11) \|$ & $P$ value \\
\hline \multicolumn{4}{|l|}{ Postoperative results } \\
\hline Reopening required, $\mathrm{n}(\%)$ & $7(21.2)$ & $2(18.2)$ & 1 \\
\hline Delay to final sternal closure (d) & $1.03(0.6-1.5)$ & $0.64(0.18-1.0)$ & .18 \\
\hline Delay to final drain removal $(d)^{*}$ & $6.75(3.35-10.15)$ & $5.95(0.66-11.16)$ & .83 \\
\hline \multicolumn{4}{|l|}{ Inotrope score ${ }^{*}$} \\
\hline ITU arrival & $26.2(18.8-33.6)$ & $26.2(19.9-32.5)$ & .47 \\
\hline ITU arrival $+48 \mathrm{~h}$ & $15(8.2-21.8)$ & $10.6(7.2-14.1)$ & .84 \\
\hline \multicolumn{4}{|l|}{ LA pressure (mm Hg) } \\
\hline ITU arrival & $8.4(7.3-9.4)$ & $7.7(6.7-8.7)$ & .33 \\
\hline ITU arrival $+48 \mathrm{~h}$ & $8.6(7.4-9.9)$ & $10.5(8.1-12.9)$ & .14 \\
\hline Delay to extubation $(\mathrm{h})^{*}$ & $127.3(65.7-188.8)$ & $43.6(29.6-57.3)$ & .19 \\
\hline Delay to ITU discharge $(d)^{*}$ & $9.4(3.6-15.2)$ & $2.9(2.3-3.5)$ & .07 \\
\hline Postoperative length of stay $(d)^{*}$ & $26.9(13.4-38.8)$ & $16.2(8.6-23.7)$ & .43 \\
\hline Peritoneal dialysis, n (\%) & $3(9.6)$ & $0(0)$ & .56 \\
\hline New CHB requiring PPM, $\mathrm{n}(\%)$ & $7(21.2)$ & $0(0)$ & .17 \\
\hline $\mathrm{mLV}$ function at discharge, $\mathrm{n}(\%)$ & & & .7 \\
\hline Good function & $23(74.2)$ & $7(63.6)$ & \\
\hline Moderate-to-severe function & $8(25.8)$ & $4(36.4)$ & \\
\hline NYHA, n (\%) & & & 1 \\
\hline $\mathrm{I} / \mathrm{II}$ & $23(79.3)$ & $9(81.8)$ & \\
\hline III/IV & $6(20.7)$ & $2(22.2)$ & \\
\hline ACEI, n (\%) & & & 1 \\
\hline Not required & $10(41.7)$ & $3(33.3)$ & \\
\hline Required & $14(58.3)$ & $5(66.7)$ & \\
\hline Diuretics, n (\%) & & & .06 \\
\hline Not required & $12(50)$ & $1(11.1)$ & \\
\hline Required & $12(50)$ & $8(88.9)$ & \\
\hline \multicolumn{4}{|l|}{ Moderate-to-severe mLV dysfunction last follow-up, $\mathrm{n}(\%)$} \\
\hline All patients & $6(19.4)$ & $6(54.5)$ & .05 \\
\hline Good mLV before DS procedure $\dagger$ & $5(20)$ & $6(60)$ & .04 \\
\hline Early mortality, n (\%) & $2(6.1)$ & $0(0)$ & 1 \\
\hline Overall mortality, n (\%) & $4(12.1)$ & $1(9.1)$ & 1 \\
\hline Death/transplantation, n (\%) & $5(15.1)$ & $2(18.2)$ & 1 \\
\hline $\begin{array}{l}\text { Death/transplantation } \pm \text { moderate-to-severe } \mathrm{mLV} \\
\text { dysfunction last follow-up, } \mathrm{n}(\%)\end{array}$ & $7(21.2)$ & $5(45.5)$ & .14 \\
\hline $\begin{array}{l}\text { Delay to death/transplantation } \pm \text { moderate-to-severe } \\
\mathrm{mLV} \text { dysfunction (d), median }\end{array}$ & $1435(212-2573)$ & $568(113-1351)$ & .10 \\
\hline Follow-up (d), median & $1435(285-2570)$ & $568(113-1465)$ & .14 \\
\hline
\end{tabular}

For the definition of morphologic left ventricle conditioning time, see the text. Medians are presented with the $25 \%$ to $75 \%$ interquartile limits and compared by means of the Mann-Whitney $U$ test. Means are presented with the $95 \%$ confidence limits and compared by using the independent-variables $t$ test. Proportions are compared by using the $\chi^{2}$ or Fisher exact tests if the numbers in the cell were 5 or less. $m L V$, Morphologic left ventricle; $A S D$, atrial septal defect; $P F O$, patent foramen ovale; $C H B$, complete heart block; $D S$, double-switch; $m R V$, morphologic right ventricle; $C P B$, cardiopulmonary bypass; $A X C$, aortic crossclamp; DHCA, deep hypothermic circulatory arrest; ITU, intensive therapy unit; PPM, permanent pacemaker; NYHA, New York Heart Association (dyspnea scale); $A C E I$, angiotensin-converting enzyme inhibitor. ${ }^{*}$ Data were log transformed to account for skewed division. †Denominator is based on the associated subgroup and not the whole group. \|Factor used in multivariate analysis.

\section{Early Outcomes}

More information on early outcomes is available in Table 1. In the $\mathrm{mLV}$ not requiring training group, there were 2 (4.5\%) early deaths, a 2.5 -year-old girl with a VSD, mLVOTO, and good $\mathrm{mLV}$ function who died during the operation from low cardiac output state and a 26-year-old man who underwent coarctation repair as an infant and subsequently presented with CCF/PHT and who died on postoperative day 3 from low cardiac output state.
Inotrope scores and left atrial pressures were similar between groups at ITU arrival and at 48 hours. In the group not requiring $\mathrm{mLV}$ training, 1 (3\%) of 33 patients required extracorporeal membrane oxygenation, and $7(21.2 \%)$ of 33 patients with complete heart block required permanent pacing. Only 1 of these had mLVOTO requiring subvalvular resection during the DS procedure. Although the delay to extubation and to ITU discharge was almost 3 -fold longer for the group not requiring training, this did not reach 
statistical significance. The postoperative hospital stay was 10 days longer for the group not requiring training.

\section{Late Outcomes}

Information on late outcomes is available in Table 1. Of the 42 patients surviving to discharge, follow-up was longer for the group not requiring training, although this did not reach statistical significance. The group not requiring training experienced 2 further deaths and 1 cardiac transplantation after the DS procedure. One underwent aortic valve replacement for aortic regurgitation (AR). In the group requiring training, there was 1 sudden death and 1 cardiac transplantation. An additional aortic valve replacement for severe AR was performed in this group.

The overall incidence of death/transplantation, development of moderate-to-severe mLV dysfunction, or both was no different between groups (Table 1). Actuarial freedom from death/transplantation was similar between groups $(P=.65$; Figure 1, $A)$, but freedom from death/transplantation, moderate-to-severe $\mathrm{mLV}$ dysfunction, or both was superior for patients who required no training $(P=.04$; Figure 1, $B$ ). The difference between Figure 1, $A$, and Figure 1, $B$, reflects the prevalence of patients alive but experiencing moderate-to-severe $\mathrm{mLV}$ dysfunction (Figure $1, C$ ). It demonstrates that patients completing $\mathrm{mLV}$ training had an increased prevalence of survivors with $\mathrm{mLV}$ dysfunction throughout the follow-up period, although this difference began to decrease with time as the prevalence of patients completing $\mathrm{mLV}$ training and surviving with moderate-to-severe dysfunction decreased. At 1 year after surgical intervention, $39 \%$ of patients who completed $\mathrm{mLV}$ training were alive with moderate-to-severe $\mathrm{mLV}$ dysfunction compared with $6.3 \%$ of patients whose mLV required no training. Moderate-to-severe $\mathrm{mLV}$ dysfunction before the DS procedure (mLV not requiring training, $\mathrm{n}=7 ; \mathrm{mLV}$ receiving training, $\mathrm{n}=1$ ) did not influence the development of $\mathrm{mLV}$ dysfunction after surgical intervention. One patient died 3 days after the DS procedure, whereas the remaining 7 patients demonstrated an improvement in $\mathrm{mLV}$ function. One of these patients subsequently had $\mathrm{mLV}$ dysfunction and died at 5 months. Actuarial freedom from death/transplantation, development of moderate-to-severe $\mathrm{mLV}$ dysfunction, or both was similar for patients with good preoperative $\mathrm{mLV}$ function and patients with moderate-to-severe $\mathrm{mLV}$ dysfunction before surgical intervention $(P=.310)$.

Multivariate analysis of preoperative variables (Table 1) demonstrated that moderate-to-severe $\mathrm{mRV}$ dysfunction before the DS procedure ( $P=.01$; hazard ratio, $9.8 ; 95 \%$ confidence limits, 1.7-54) and the successful completion of $\mathrm{mLV}$ training before the DS procedure $(P=.02$; hazard ratio, $0.19 ; 95 \%$ confidence limits, $0.05-0.76)$ were independent predictors of death/transplantation, the development of $\mathrm{mLV}$ dysfunction, or both before the DS procedure.
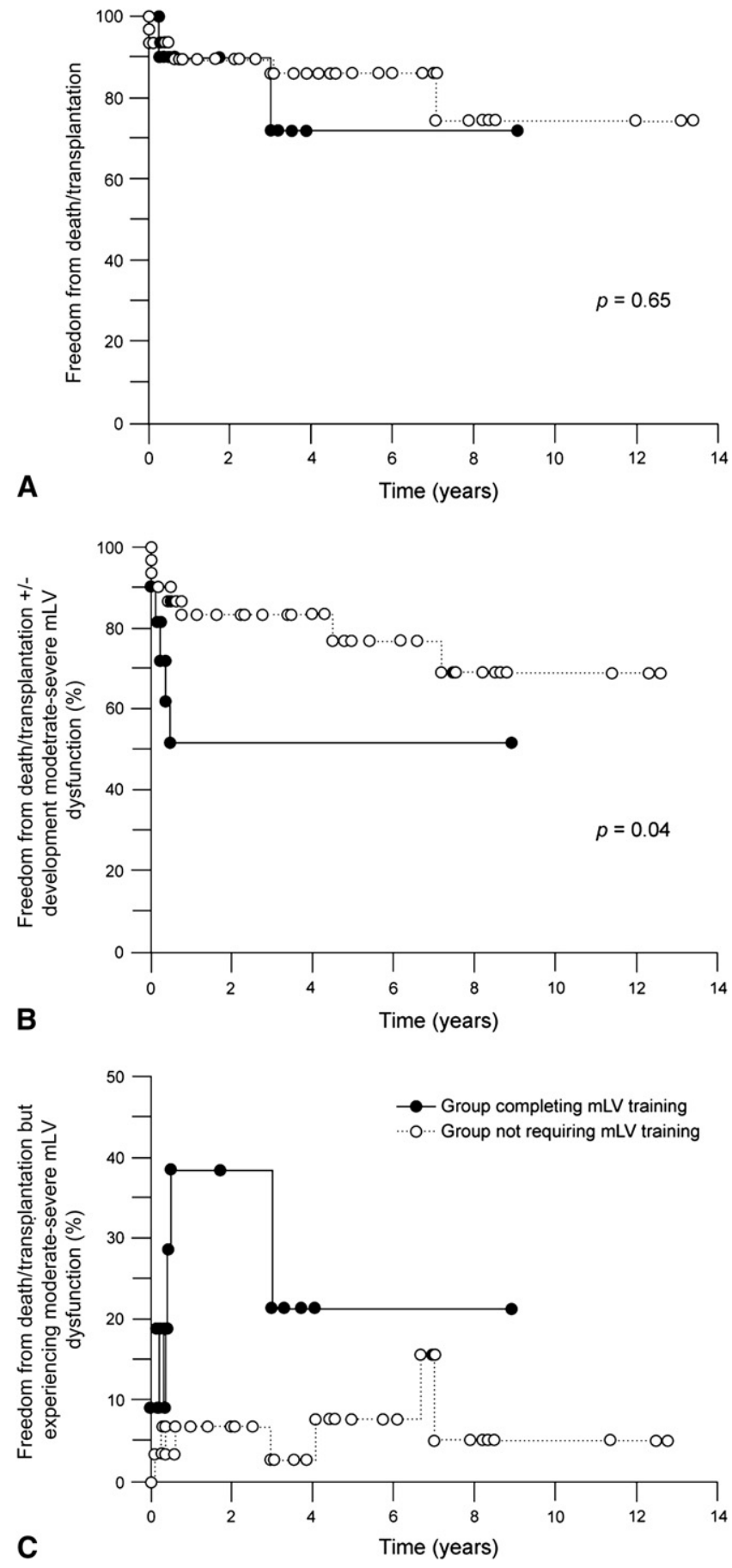

Figure 1. A comparison of freedom from death/transplantation after the double-switch procedure $(A)$; death/transplantation, moderate-to-severe morphologic left ventricle $(m L V)$ dysfunction, or both after the double-switch procedure (B); and the actuarial prevalence of patients free from death/transplantation but with moderate-to-severe $\mathrm{mLV}$ dysfunction (C). 


\section{Atrioventricular and Semilunar Valve Function}

More information on atrioventricular and semilunar valve function is available in Figure E2. There was no difference between groups in the incidence of moderate-to-severe TR at diagnosis (ie, before PA banding) or before DS. There was no difference $(P=.11)$ between the incidence of moderate-to-severe TR in the group requiring $\mathrm{mLV}$ training $(8 / 11$ [72.2\%] before PA banding) and in those not requiring training (15/33 [45\%]) before the DS procedure. At discharge after the DS procedure, the incidence of moderate-to-severe TR decreased in the group not requiring training but remained increased in the trained mLV group. At last follow-up, the incidence of moderate-to-severe TR had decreased in both groups to statistically comparable values. There was no significant difference in the incidence of mitral regurgitation between groups at diagnosis before or after the DS procedure. The incidence of AR was similar between groups at diagnosis and before the DS procedure, but after the DS procedure, regurgitation through the new aortic valve (neoAR) increased comparably in both groups at discharge and last follow-up.

\section{Discussion}

This is one of the largest cohorts of the DS procedure reported. The demographics, preoperative variables, and postoperative results are similar to those of previous studies. ${ }^{11,14,18}$ The data demonstrate that patients who complete mLV training by means of PA banding have comparable early postoperative recoveries with those not requiring training but were more likely to have deterioration to moderate-tosevere mLV dysfunction at an earlier stage compared with patients who did not require training.

The restoration of the mLV to the systemic circulation by the DS procedure might reduce the incidence of systemic ventricular failure and midterm mortality associated with conventional repair. The reduction in TR after the DS procedure might reflect this. ${ }^{19,20}$ However, patients with CCTGA are heterogeneous for cardiac morphology and presentation. The similarities in early outcome between the groups occurred despite differences in age, weight, and clinical condition. This suggests that training, selection, and technique produced equivalent pre-DS and early postoperative mLV function.

Patients with involution of the mLV need to be identified and considered for training by means of PA banding. This stimulates an increase in mLV mass as early as 4 days and is associated with improvements in absolute contractility and ejection fraction. ${ }^{21,22}$ It has become an established method of preparatory training for the arterial switch procedure in patients with the related condition of d-transposition of the great arteries and for the DS procedure in patients with CCTGA. Assessment of training was by means of echocardiographic and cardiac catheterization data in this study. Other techniques, such as magnetic resonance imaging, might provide additional information. $^{23}$
The durability of mLV function after training by means of PA banding has been questioned by these and previous data that highlight a low but appreciable incidence of the trained mLV failure after the DS procedure. The reasons might include the development of a neoAR after the DS procedure or a detrimental effect of training by means of PA banding on $\mathrm{mLV}$ function. NeoAR is a recognized complication after the DS procedure and can be more frequent in patients whose PAs have been distorted by means of PA banding. The small number of patients in this series was unable to detect differences in neoAR, and its influence on $\mathrm{mLV}$ function remains unclear.

Animal experiments suggest that technique, timing, and duration of training by means of PA banding might adversely affect long-term mLV function. In this trial the technique of PA banding used was an independent predictor of mLV dysfunction. It might cause subendocardial edema, myocardial necrosis, and fibrosis ${ }^{24}$ and reduced ventricular work index. ${ }^{25}$ Experimentally, initial relatively tight sustained banding, akin to the clinical technique described in this study, might produce fibrosis and limit increases in ventricular pressure more than a regimen of twice daily intermittent band tightening. ${ }^{26}$ The use of a looser banding circumference with an initially lower $\mathrm{mLV} / \mathrm{mRV}(0.5-0.67)$ pressure ratio increasingly gradually with relative PA growth ${ }^{11}$ or the use of adjustable banding (without reoperation) to tailor the PA circumference to its training requirements ${ }^{27}$ are clinical alternatives to our technique. However, less-aggressive banding techniques have also been associated with decreases in $\mathrm{mLV}$ function after the DS procedure, ${ }^{18}$ and the contribution of these techniques to $\mathrm{mLV}$ has not been directly compared in clinical trials. The adjustable banding technique is an attractive proposition but yet to be fully evaluated.

Age of banding might determine the later function of the myocardium. The hypertrophic response to afterload training is accompanied by hyperplasia in younger, less mature hearts. This is less prevalent in more mature hearts. ${ }^{28}$ When considering $\mathrm{mLV}$ training, hypertrophy is an adaptive phenomenon with beneficial short-term but possibly adverse long-term consequences. Adult patients with mLV hypertrophy caused by hypertension or aortic stenosis are at risk of adverse cardiovascular events. ${ }^{29}$ The quality of hypertrophy might account for the less effective durability of $\mathrm{mLV}$ training in older patients.

\section{Study Limitations}

The study is limited by its retrospective design, which might include bias to the degree of $\mathrm{mLV}$ dysfunction. The data from echocardiographic results were dichotomized into normal-to-mild and moderate-to-severe, which limits the degree of error in assessment and, at the time of blinded review, was not influenced by knowledge of the patient's clinical condition. The 13-year period of surgical experience might have been associated with changes in selection and 
management of patients undergoing the DS procedure that could influence early and midterm results.

\section{Conclusion}

Our technique for mLV training by means of PA banding adequately prepares the mLV for the DS procedure and allows early post-DS results to compare favorably with those of patients whose $\mathrm{mLV}$ requires no training. In the intermediate term there is an increased risk of deterioration of $\mathrm{mLV}$ function over time, and these patients need to be followed up regularly in order to detect this.

\section{References}

1. Alva C, Horowitz E, Ho SY, et al. The feasibility of complete anatomical correction in the setting of discordant atrioventricular connections. Heart. 1999;81:539-45.

2. Van Praagh R, Papagiannis J, Grunenfelder J, et al. Pathologic anatomy of corrected transposition of the great arteries: medical and surgical implications. Am Heart J. 1998;135:772-85.

3. Hornung TS, Bernard EJ, Celermajer DS, et al. Right ventricular dysfunction in congenitally corrected transposition of the great arteries. Am J Cardiol. 1999;84:1116-9, A1110.

4. Hauser M, Bengel FM, Hager A, et al. Impaired myocardial blood flow and coronary flow reserve of the anatomical right systemic ventricle in patients with congenitally corrected transposition of the great arteries. Heart. 2003;89:1231-5.

5. Sano T, Riesenfeld T, Karl TR, et al. Intermediate-term outcome after intracardiac repair of associated cardiac defects in patients with atrioventricular and ventriculoarterial discordance. Circulation. 1995;92(suppl): II272-8.

6. Prieto LR, Hordof AJ, Secic M, et al. Progressive tricuspid valve disease in patients with congenitally corrected transposition of the great arteries. Circulation. 1998;98:997-1005.

7. van Son JA, Danielson GK, Huhta JC, et al. Late results of systemic atrioventricular valve replacement in corrected transposition. $J$ Thorac Cardiovasc Surg. 1995;109:642-52.

8. Huhta JC, Danielson GK, Ritter DG, et al. Survival in atrioventricular discordance. Pediatr Cardiol. 1985;6:57-60.

9. Hraska V, Duncan BW, Mayer JE Jr, et al. Long-term outcome of surgically treated patients with corrected transposition of the great arteries. J Thorac Cardiovasc Surg. 2005;129:182-91.

10. Ilbawi MN, Ocampo CB, Allen BS, et al. Intermediate results of the anatomic repair for congenitally corrected transposition. Ann Thorac Surg. 2002;73:594-600.

11. Duncan BW, Mee RB, Mesia CI, et al. Results of the double switch operation for congenitally corrected transposition of the great arteries. Eur J Cardiothorac Surg. 2003;24:11-20.

12. Langley SM, Winlaw DS, Stumper O, et al. Midterm results after restoration of the morphologically left ventricle to the systemic circulation in patients with congenitally corrected transposition of the great arteries. J Thorac Cardiovasc Surg. 2003;125:1229-41.
13. Helvind $\mathrm{MH}$, McCarthy JF, Imamura $\mathrm{M}$, et al. Ventriculo-arterial discordance: switching the morphologically left ventricle into the systemic circulation after 3 months of age. Eur J Cardiothorac Surg. 1998;14:173-8.

14. Devaney EJ, Charpie JR, Ohye RG, et al. Combined arterial switch and Senning operation for congenitally corrected transposition of the great arteries: patient selection and intermediate results. J Thorac Cardiovasc Surg. 2003;125:500-7.

15. Alousi AA, Johnson DC. Pharmacology of the bipyridines: amrinone and milrinone. Circulation. 1986;73(suppl):III10-24.

16. Winlaw DS, McGuirk SP, Balmer C, et al. Intention-to-treat analysis of pulmonary artery banding in conditions with a morphological right ventricle in the systemic circulation with a view to anatomic biventricular repair. Circulation. 2005;111:405-11.

17. Devaney EJ, Ohye RG, Bove EL. Technical aspects of the combined arterial switch and Senning operation for congenitally corrected transposition of the great arteries. Semin Thorac Cardiovasc Surg Pediatr Card Surg Anпи. 2003;6:9-15.

18. Sharma R, Bhan A, Juneja R, et al. Double switch for congenitally corrected transposition of the great arteries. Eur J Cardiothorac Surg. 1999;15:276-81.

19. Karl TR, Weintraub RG, Brizard CP, et al. Senning plus arterial switch operation for discordant (congenitally corrected) transposition. Ann Thorac Surg. 1997;64:495-502.

20. Imamura M, Drummond-Webb JJ, Murphy DJ Jr, et al. Results of the double switch operation in the current era. Ann Thorac Surg. 2000;70: $100-5$

21. Boutin C, Jonas RA, Sanders SP, et al. Rapid two-stage arterial switch operation. Acquisition of left ventricular mass after pulmonary artery banding in infants with transposition of the great arteries. Circulation. 1994;90:1304-9.

22. Hon JK, Steendijk P, Khan H, et al. Acute effects of pulmonary artery banding in sheep on right ventricle pressure-volume relations: relevance to the arterial switch operation. Acta Physiol Scand. 2001;172:97-106.

23. Salehian O, Schwerzmann M, Merchant N, et al. Assessment of systemic right ventricular function in patients with transposition of the great arteries using the myocardial performance index: comparison with cardiac magnetic resonance imaging. Circulation. 2004;110:3229-33.

24. Davis KL, Laine GA, Geissler HJ, et al. Effects of myocardial edema on the development of myocardial interstitial fibrosis. Microcirculation. 2000;7:269-80.

25. Muhlfeld C, Coulibaly M, Dorge H, et al. Ultrastructure of right ventricular myocardium subjected to acute pressure load. Thorac Cardiovasc Surg. 2004;52:328-33.

26. Le Bret E, Lupoglazoff JM, Borenstein N, et al. Cardiac "fitness" training: an experimental comparative study of three methods of pulmonary artery banding for ventricular training. Ann Thorac Surg. 2005;79: 198-203.

27. Bonnet D, Corno AF, Sidi D, et al. Early clinical results of the telemetric adjustable pulmonary artery banding FloWatch-PAB. Circulation. 2004;110(suppl 1):II158-63.

28. Le Bret E, Bonhoeffer P, Folliguet TA, et al. A new percutaneously adjustable, thoracoscopically implantable, pulmonary artery banding: an experimental study. Ann Thorac Surg. 2001;72:1358-61.

29. Vakili BA, Okin PM, Devereux RB. Prognostic implications of left ventricular hypertrophy. Am Heart J. 2001;141:334-41. 


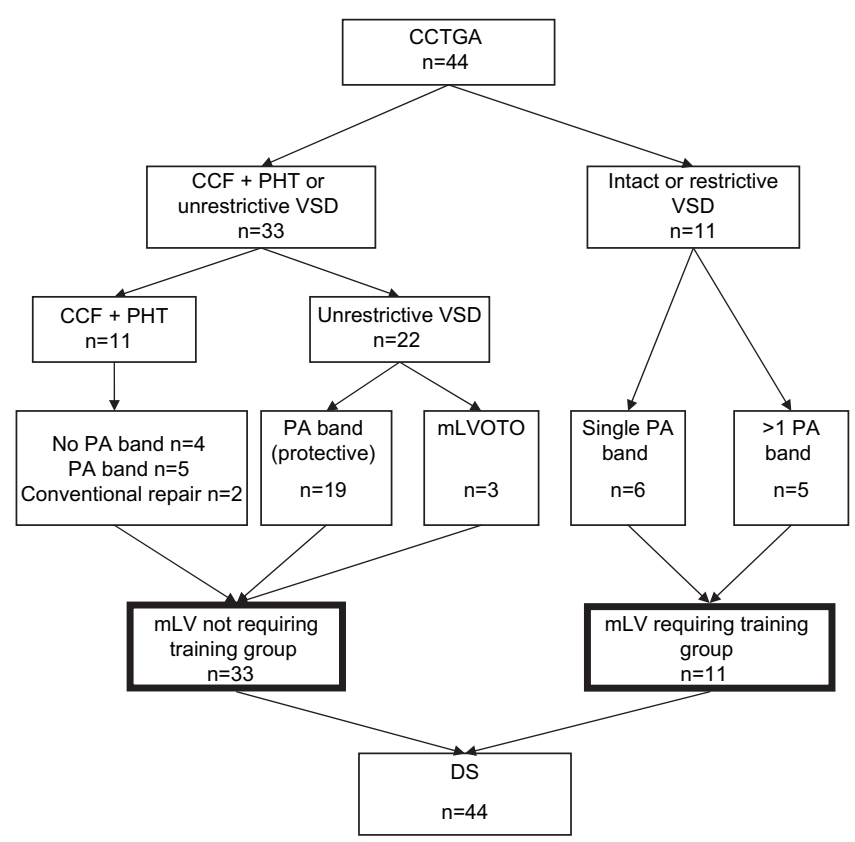

Figure E1. The characterization of patient groups undergoing the DS procedure. The bold-bordered boxes represent the final grouping of patients (untrained $\mathrm{mLV}$ group CCF and PHT, $n=11$; VSD with proactive PA banding $\mathrm{mLVOTO}, \mathrm{n}=22$; trained $\mathrm{mLV}$ group by means of PA banding for $\mathrm{mLV}$ training, $n=11$ ). CCTGA, Congenitally corrected transposition of the great arteries; CCF, congestive cardiac failure; $P H T$, pulmonary hypertension; VSD, ventricular septal defect; $P A$, pulmonary artery; $m L V O T O$, morphologic left ventricular outflow tract; $m L V$, morphologic left ventricle. 

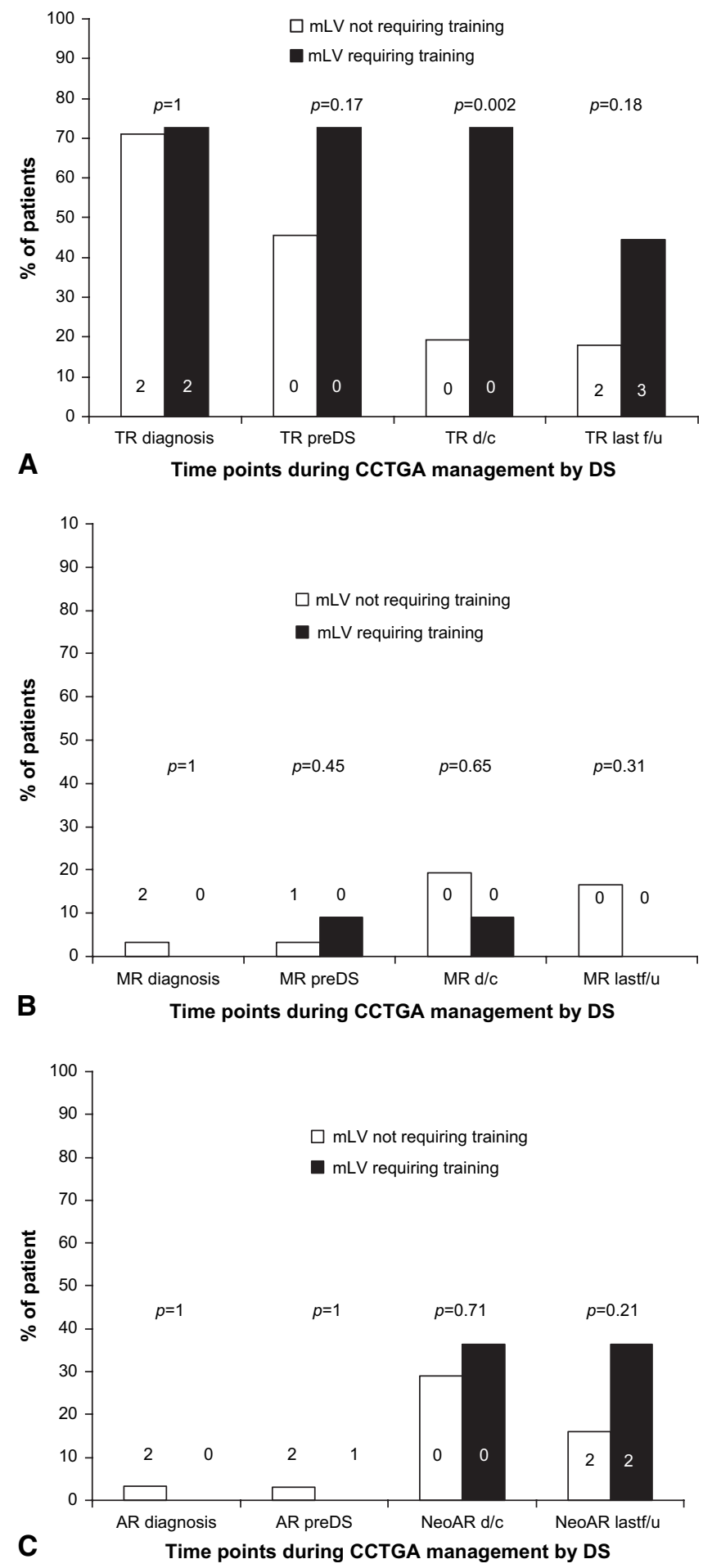

Figure E2. A comparison of moderate-to-severe valvular regurgitation between groups: $A$, tricuspid valve (Factor used in multivariate analysis); $B$, mitral valve; $C$, aortic valve. $m L V$, Morphologic left ventricle; $T R$, tricuspid regurgitation; $D S$, double-stitch procedure; $d / c$, discharge; $f / u$, follow-up; CCTGA, congenitally corrected transposition of the great arteries; $M R$, mitral regurgitation; $A R$, aortic regurgitation. Numbers on graph represent missing values. 